\title{
Assessing the expression of immunosuppressive cytokines in the newly diagnosed systemic lupus Erythematosus patients: a focus on B cells
}

Mitra Abbasifard ${ }^{1}$, Zahra Kamiabo,3, Mohammad Hasani ${ }^{1}$, Amir Rahnama ${ }^{4}$, Pooya Saeed-Askari ${ }^{1}$ and Hossein Khorramdelazad ${ }^{5^{*}}$ (D)

\begin{abstract}
Background: The immunosuppressive effects of regulatory B-cells (Bregs) and their immunosuppressive cytokines on immune responses in autoimmune disorders, mainly systemic lupus erythematosus (SLE), have been recently established. Therefore, the purpose of this article has been the exploration of the expressions of cytokines produced by B cells in newly diagnosed SLE patients.

Results: The findings demonstrated that the gene expression of IL-10, TGF- $\beta$, IL-35, PD-L1, and FasL was significantly up-regulated in SLE patients compared to healthy subjects $(P<0.05)$. Additionally, the results revealed that serum levels of IL-10, TGF- $\beta$, IL-35, PD-L1 were remarkably increased in patients with SLE compared to healthy subjects $(P<0.0001)$. However, serum levels of IL-10 and TGF- $\beta$ decreased significantly with increasing SLEDAI score in studied patients $(P<0.05)$.

Conclusion: It was concluded that the release of anti-inflammatory cytokines, particularly IL-10 and TGF- $\beta$, might inhibit immune responses and autoreactive immune cells in a compensatory manner in SLE patients with mild to moderate disease activity.
\end{abstract}

Keywords: Regulatory B-cells (Bregs), Systemic lupus Erythematosus (SLE), Anti-inflammatory cytokine

\section{Background}

The systemic lupus erythematosus (SLE) is a multifactorial chronic autoimmune disease that is more common in women [1]. Evidence showed that genetic and environmental factors, including cigarette smoking, drugs, ultraviolet (UV) light, chemical substances, gut microbiota, and viral infections, could be involved in SLE onset $[1,2]$. Regarding the existence of an imbalance between apoptosis and removal of apoptotic substances

\footnotetext{
* Correspondence: khorramdelazad@gmail.com

${ }^{5}$ Department of Immunology, School of Medicine; Molecular Medicine Research Center, Research Institute of Basic Medical Sciences, Rafsanjan University of Medical Sciences, Rafsanjan, Iran

Full list of author information is available at the end of the article
}

in SLE patients, nuclear antigens such as histones, centromere proteins, single- and double-stranded deoxyribonucleic acid (ss- and ds-DNA), nucleosome, Smith antigen ( $\mathrm{Sm} \mathrm{Ag),} \mathrm{Ro} \mathrm{and} \mathrm{La} \mathrm{proteins,} \mathrm{as} \mathrm{well} \mathrm{as} \mathrm{ribonu-}$ cleoproteins (RNPs) become exposed to the immune system cells and components [3]. These autoantigens are able to stimulate B-cells to produce auto-antibodies such as anti-nuclear antibody (ANA) and anti-doublestranded DNA (ds-DNA) antibody as well as other inflammatory mediators [4].

Previous studies revealed that regulatory immune cells, such as regulatory $\mathrm{T}$ cells (Tregs) and $\mathrm{B}$ regs with immunosuppressive properties, are involved in the

C C The Author(s). 2020 Open Access This article is licensed under a Creative Commons Attribution 4.0 International License, which permits use, sharing, adaptation, distribution and reproduction in any medium or format, as long as you give appropriate credit to the original author(s) and the source, provide a link to the Creative Commons licence, and indicate if changes were made. The images or other third party material in this article are included in the article's Creative Commons licence, unless indicated otherwise in a credit line to the material. If material is not included in the article's Creative Commons licence and your intended use is not permitted by statutory regulation or exceeds the permitted use, you will need to obtain permission directly from the copyright holder. To view a copy of this licence, visit http://creativecommons.org/licenses/by/4.0/ The Creative Commons Public Domain Dedication waiver (http://creativecommons.org/publicdomain/zero/1.0/) applies to the data made available in this article, unless otherwise stated in a credit line to the data. 
homeostasis processes [5]. Recent experimental and human studies have further indicated that Bregs can suppress inflammatory responses via production and secretion of anti-inflammatory cytokines like IL-10, IL35 , and TGF- $\beta$ as well as expression of inhibitory molecules [6, 7]. Besides, Bregs come up from common progenitor of transitional 2-marginal zone precursor (T2-MZP) B cells capable of being autoreactive following interaction with pathogens and even activating release anti-inflammatory mediators [8]. Some investigations in this respect have correspondingly suggested that Bregs are impaired in inflammatory autoimmune disorders such as SLE, rheumatoid arthritis (RA), and Graves' disease [9]. However, signals necessary for differentiation of Bregs have remained poorly understood, and previous studies have revealed that, under normal conditions, plasmacytoid dendritic cells (pDCs) would stimulate differentiation of $\mathrm{CD} 19+\mathrm{CD} 24^{\mathrm{hi}} \mathrm{CD} 38^{\mathrm{hi}}$ immature B-cells into the $\mathrm{CD} 24^{+} \mathrm{CD} 38^{\text {hi }}$ mature Bregs, which could produce IL-10 through release of interferon-alpha (IFN- $\alpha$ ) and the cluster of differentiation 40 (CD40) engagement. Conversely, the mentioned Bregs can have an inhibitory effect on the generation of IFN- $\alpha$ through pDCs by releasing IL-10 [10]. In SLE, the cross-talk between pDCs and Bregs has defected, and pDCs fail to trigger differentiating $\mathrm{CD} 19^{+} \mathrm{CD} 24^{\mathrm{hi}} \mathrm{CD} 38^{\text {hi }}$ B-cells into IL-10producing $\mathrm{CD} 24^{+} \mathrm{CD} 38^{\mathrm{hi}}$ Bregs [10]. In addition, Bregs can suppress $\mathrm{CD} 4^{+} \mathrm{T}$-cell proliferation, induce Foxp $3^{+}$ regulatory $\mathrm{T}$ and $\mathrm{Tr} 1$ cells, and suppress $\mathrm{T}$ helper (Th) 1 (Th1). Bregs also can stimulate Th17 and $\mathrm{CD}^{+}$effector $\mathrm{T}$-cells differentiation through cell-cell interactions and release of the anti-inflammatory cytokine, including TGF- $\beta$, IL-35, and IL-10. As well, TGF- $\beta$ and IL-10, which are secreted by Bregs, can have an inhibitory effect on antigen-presenting function, cytokine secretion by DCs, neutrophils, natural killer (NK) cells, M1 macrophages, and conversely, induction of M2 macrophage differentiation.

Moreover, FasL (or CD178) or PD-L1 (or CD274) that are expressed on the Bregs surface are involved in the apoptosis of effector $\mathrm{T}$ cells following ligation with PD-1 (CD279) and Fas (CD95) on the surface of mentioned Tcells [11]. Since changes in immune cells phenotype, as well as their number and function, are closely related to the disease activity, measuring the produced mediators and inhibitory molecules by regulatory immune cells before treatment based on diseases activity status could be critical in further understanding the role of the modulatory mechanisms of the immune system in the pathogenesis of SLE. Therefore, this study aimed to measure inhibitory molecules' expression on B cells' surface and anti-inflammatory cytokines produced by $\mathrm{B}$ cells in newly diagnosed SLE patients compared to healthy subjects.

\section{Results}

Twenty-three patients suffering from SLE and thirty normal-age and gender-matched subjects were enrolled in this study. The demographic features of SLE patients and healthy subjects are shown in Table 1 . All the patients were classified as individuals having an active disease (SLEDAI $\geq 4$ ). The mean \pm SD of SLEDAI in patients was $9.73 \pm 6.01$ and we divided patients into three groups (SLEDAI I; 4 to 7, SLEDAI II; 7 to10, SLEDAI III more than 10) based on SLEDAI scores (min:5, max: 34, and median: 8). At the time of the blood collection, newly diagnosed SLE patients were not under treatment. Clinical and laboratory data of studied SLE patients are shown in Table 2.

\section{mRNA and protein expression of cytokines and inhibitory molecules}

The data obtained from RT-PCR demonstrated the considerable rising trend in expressions of IL-10, IL-35 (EBI3 or IL-12P35), TGF- $\beta$, PDL-1, and FasL genes $(P<$ $0.0001)$ in the B-cell population of the SLE patients compared with ones isolated from the healthy subjects (Fig. 1). Additionally, serum levels of IL-10 (control: $115 \pm 22.1$; patient: $158 \pm 31.7 ; P<0.001$ ), IL-35 (control: $377 \pm 63.84$; patient: $499 \pm 42.95 ; \mathrm{P}<0.001$ ), and TGF- $\beta$ (control: $28 \pm 6.87$; patient: $112 \pm 19.47 ; P<0.005$ ) were significantly increased in SLE patients compared with the healthy subjects. The multiple comparison analysis in three groups of patients based on the SLEDAI score showed that by increasing disease activity, serum levels of IL-10 and TGF- $\beta$ decreased significantly $(P<0.05)$,

Table 1 Some demographic features of patients and healthy subjects enrolled in the study

\begin{tabular}{llll}
\hline Demographic features & $\begin{array}{l}\text { Control } \\
\boldsymbol{n}=\mathbf{3 0}\end{array}$ & $\begin{array}{l}\text { Patients } \\
\boldsymbol{n}=\mathbf{2 3}\end{array}$ & $\begin{array}{l}\boldsymbol{P} \text {-Value } \\
\text { Age at study (years), mean } \pm \text { SD }\end{array}$ \\
Sex (m/f) & $34.95 \pm 10.02$ & $39.60 \pm 13.45$ & 0.21 \\
BMI (kg/m2), mean \pm SD & $0 / 30$ & $0 / 23$ & - \\
Disease activity (SLEDAl), mean \pm SD & $23.87 \pm 2.97$ & $26.97 \pm 4.95$ & - \\
Smoking (\%) & - & $9.73 \pm 6.01$ & - \\
\hline
\end{tabular}

Data are presented as mean $\pm \mathrm{SD},{ }^{*}$ significant $(P<0.05)$ 


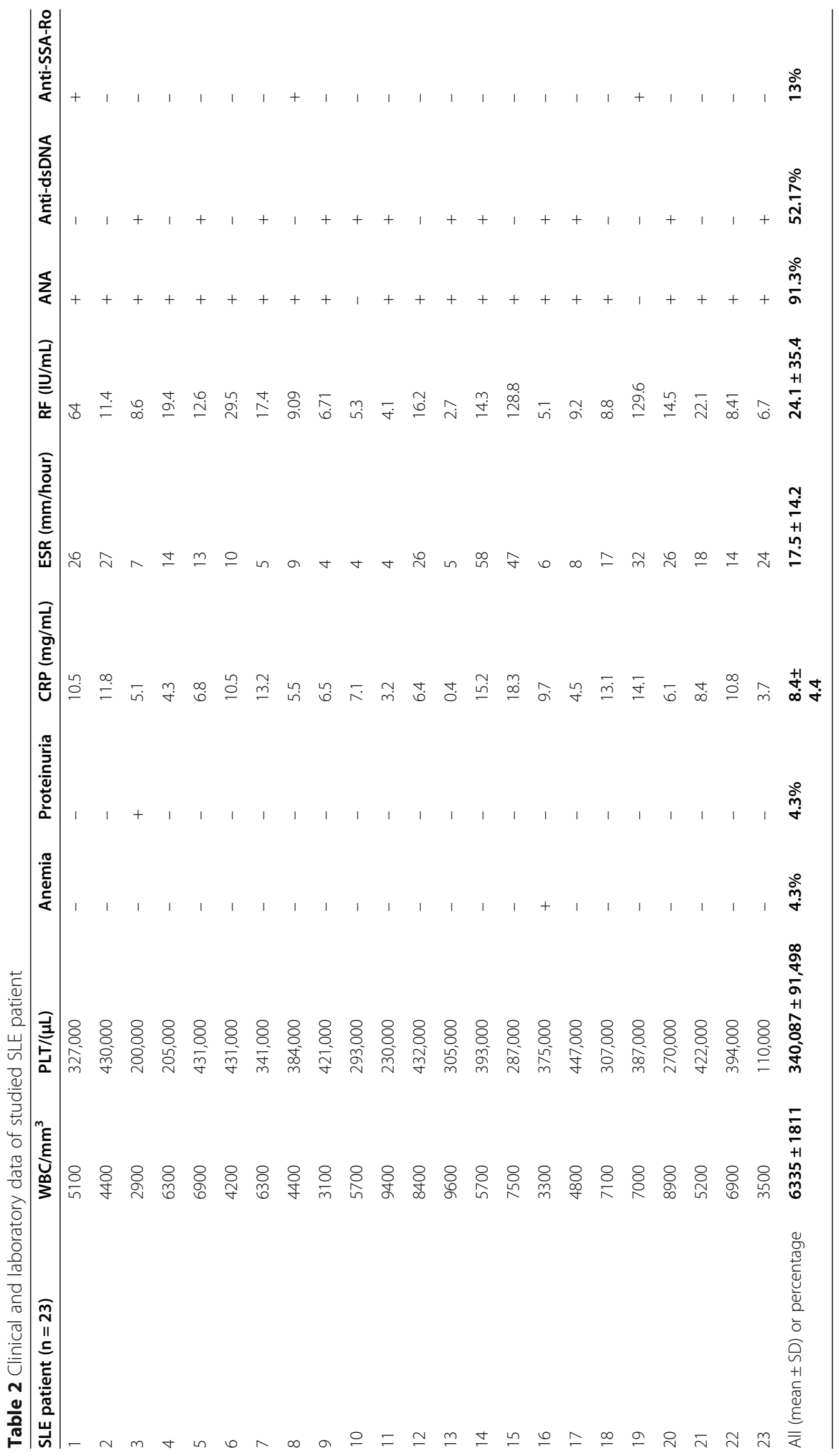




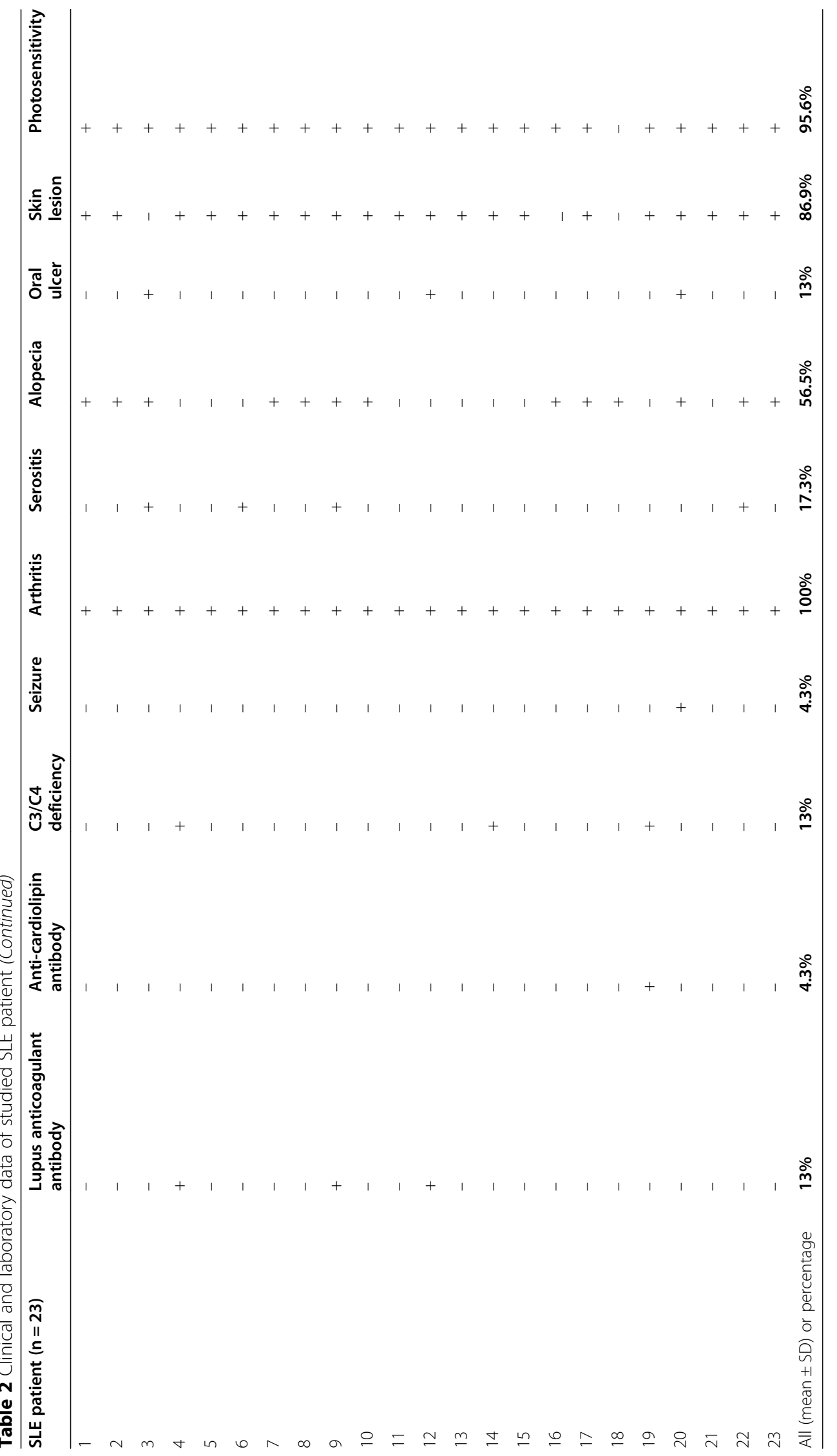




\section{A}

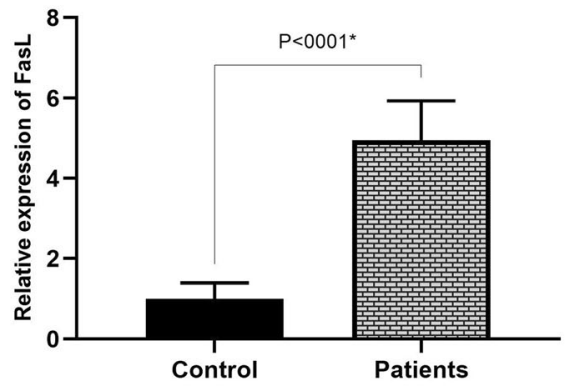

$\mathrm{C}$

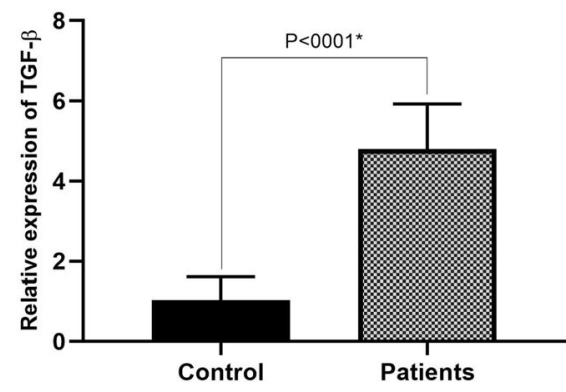

E

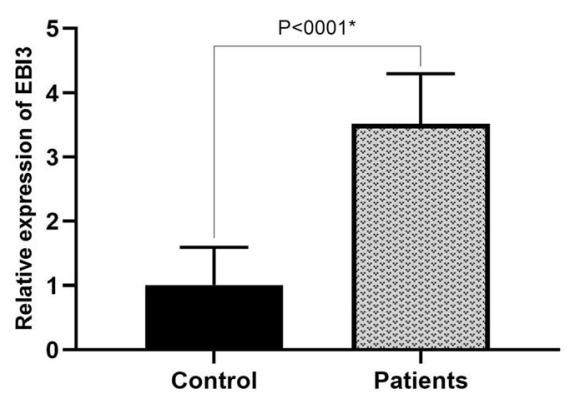

B

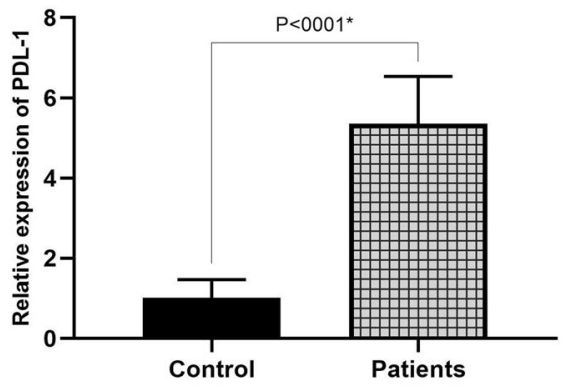

D

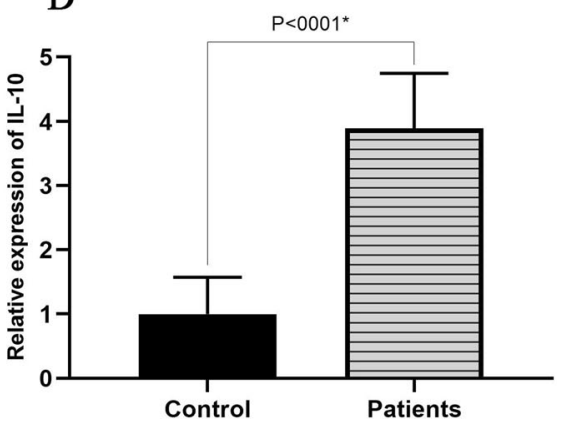

$\mathrm{F}$

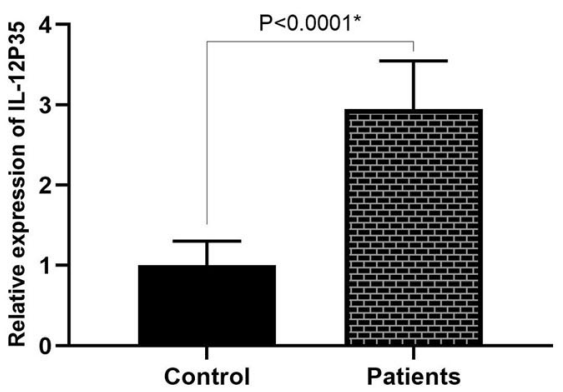

Fig. 1 Alteration in mRNA levels of FasL (a), PDL-1 [2], TGF- $\beta$ (c), IL-10 (d), EBI3 (e), and IL-12p35 (f) in control and SLE patient groups. Data are presented as mean $\pm \mathrm{SD}$, * significant $(P<0.05)$

while in the case of IL-35, a significant difference was not observed. Serum levels fluctuations in SLE patient different SLEDAI scores are shown in Fig. 2.

\section{Cytokines, autoantibodies, inhibitory molecules and disease activity}

The correlation analysis between disease activity scores and titres of autoantibodies showed that there was a positive association between ANA, anti-dsDNA, and anti-SSA/Ro with disease activity score but the correlations were not statistically significant $(\mathrm{r}=0.2, p=0.359$; $\mathrm{r}=0.108, p=0.623$; and $\mathrm{r}=0.353, p=0.1$; respectively). Correlation matrix analysis showed that there was an association between serum level of TGF- $\beta$ and SLEDAI $(\mathrm{r}=-0.54, p=0.007)$; PDL-1 gene and IL-35 serum level $(\mathrm{r}=0.53, p=0.008) ; \mathrm{IL}-10$ and TGF- $\beta$ serum levels $(\mathrm{r}=$
$0.64, p=0.001)$; IL-10 and EBI3 genes $(\mathrm{r}=-0.56, p=$ 0.05) (Fig. 3).

Moreover, information of nine variables related to studied cytokines (EBI3 gene, TGF- $\beta$, IL-10, IL-12p35, PDL-1, FasL genes and IL-10, TGF- $\beta$, and IL-35 serum levels) were extracted and converted into two components 1 , and 2 using PCA. The cumulative percent of the variance of the two components was $88.47 \%$. HCA was also used to cluster patients based on cytokine obtained data. Data showed that healthy subjects $(n=30)$ were placed in clusters 1 and 2 (blue and yellow) and to the left of the dendrogram while SLE patients $(n=23)$ were placed in clusters 3 and 4 (red and gray) and to the right of the dendrogram (Fig. 4 a). Altogether, the results showed that considering components 1 and 2 data, SLE patients could be differentiated from healthy subjects (Fig. 4 b). 

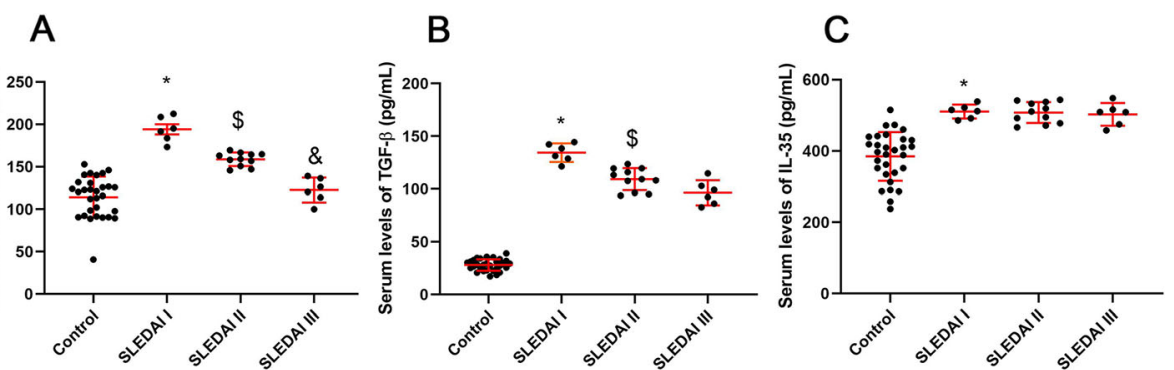

Fig. 2 The differences between serum levels of IL-10 (a), TGF- $\beta$ (b), and IL-35 (c) in healthy subjects (control) and three groups of SLE patients based on SLEDAI I; 4 to 7, SLEDAI II; 7 to 10, SLEDAI III more than 10 scores. *: significant difference between control and three SLEDAI groups, \$: significant difference between SLEDAI I and SLEDAI II groups, \&: significant difference between SLEDAI I, SLEDAI II, and SLEDAI III groups. Data are presented as mean $\pm \mathrm{SD},{ }^{*}$ significant $(P<0.05)$

Additionally, the results of regression (PCR) showed that there is only a significant inverse relationship between component 2 and SLEDAI scores because the estimated confidence interval for component 2 did not include zero; therefore, on average, with the increase of one unit of component 2 in which IL-10 plays an important role, the SLEDAI score has decreased 1.39 units (Table 3). These results suggest that there is an inverse association between SLEDAI scores and immunomodulatory cytokines.

\section{Discussion}

In this study, the expression of some inhibitory molecules and immunosuppressive cytokine in isolated B cells and sera from newly diagnosed SLE patients whose treatment had not been started was investigated. The study findings revealed that mRNA levels of IL-35 (EBI3 or IL-12p35), IL-10, and TGF- $\beta$ in isolated B-cells from SLE patients were elevated compared to healthy subjects. Moreover, the level of IL-10, TGF- $\beta$, and IL-35 serum increased in the patients' peripheral blood affected by the SLE compared with healthy subjects. The findings in three groups of patients based on SLEDAI score also demonstrated that by increasing disease activity, serum levels of IL-10 and TGF- $\beta$ decreased significantly $(P<$ $0.05)$, although, in the case of IL-35, there was no remarkable difference between groups. Additionally, the mRNA levels of PDL-1 and FasL were significantly upregulated in B-cells of the SLE patients compared to healthy subjects.

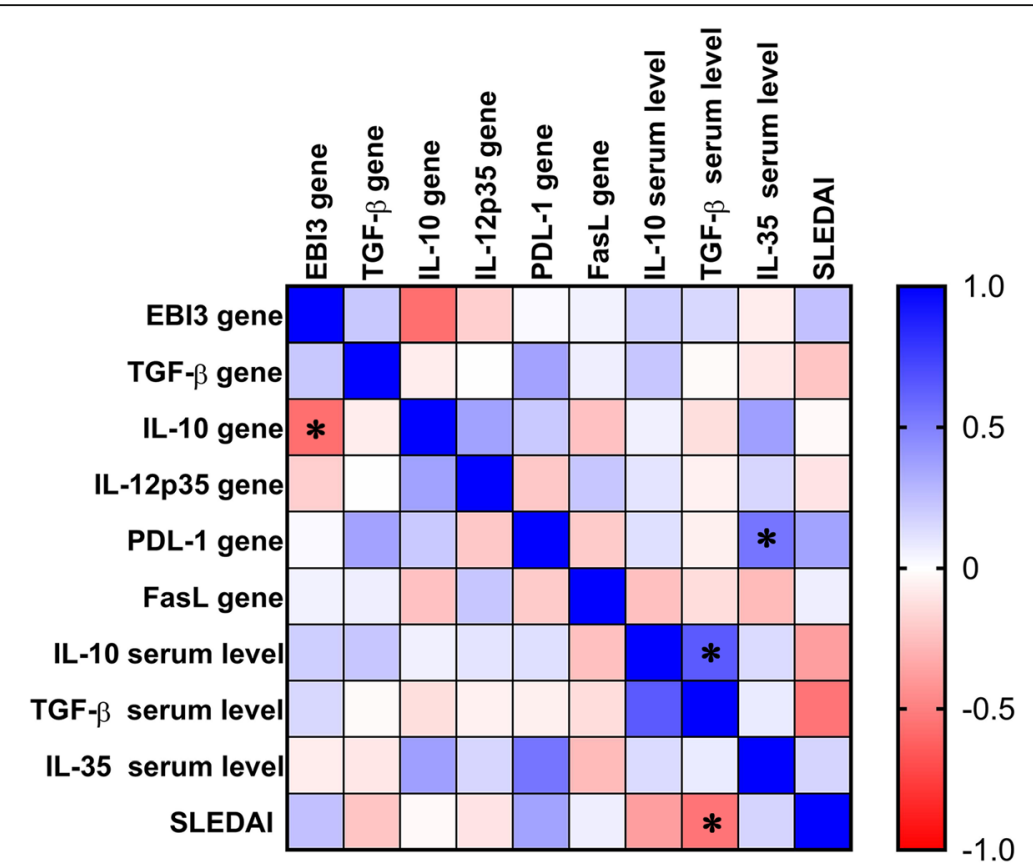

Fig. 3 The correlations between SLEDAI as the disease activity index in SLE patients and studied inhibitory molecules as well as immunosuppressive cytokines. The confidence interval of $r$ is shown in the right rectangle (between -1 and 1$).{ }^{*}$ significant $(P<0.05)$ 


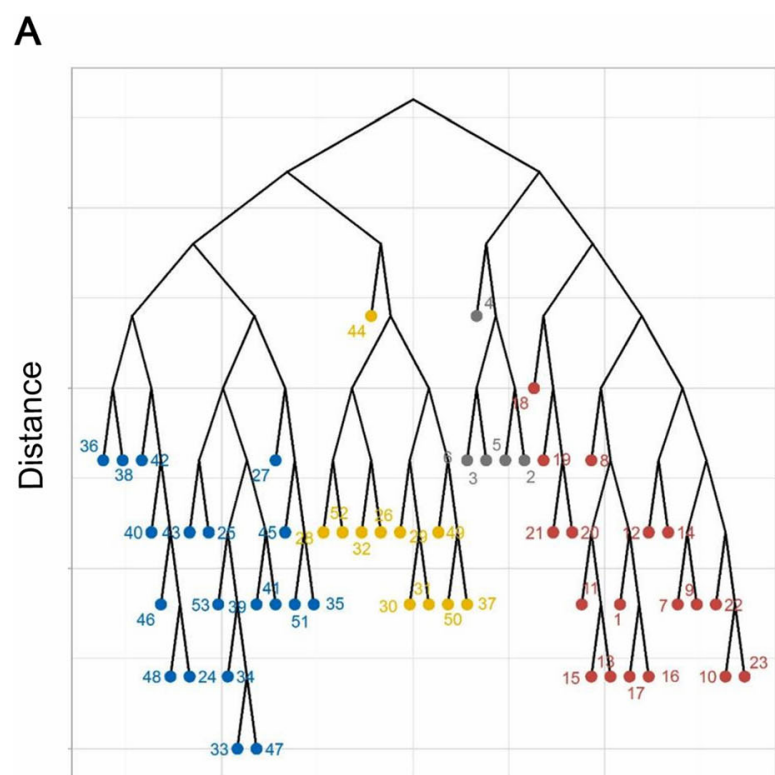

Observation
B

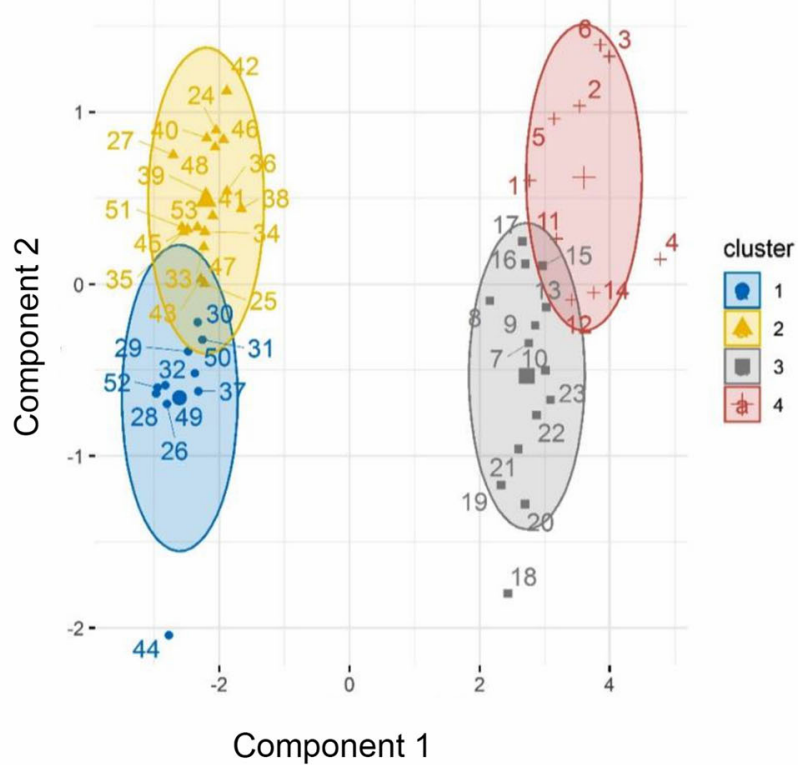

Fig. 4 Principal component analysis and clustering of cytokine profiles in newly diagnosed SLE patients $(n=23)$ and healthy subjects $(n=30)$. Information of nine variables related to studied cytokines (EBI3, TGF- $\beta$, IL-10, IL-12p35, PDL-1, FasL genes and IL-10, TGF- $\beta$, and IL-35 serum levels) were extracted and converted into two components 1, and 2 using PCA based on the loading values. The cumulative percent of the variance of the two components was 88.47. Data showed that healthy subjects were placed in clusters 1 and 2 (blue and yellow) and to the left of the dendrogram, while SLE patients were placed in clusters 3 and 4 (red and gray) and to the right of the dendrogram (a). The results also showed that by considering components 1 and 2 data extracted from the mRNA and protein levels of IL-10, TGF- $\beta$, and IL-35, SLE patients could be differentiated from healthy subjects (b)

Evidence revealed that SLE is a multiple-organ autoimmune disease described by autoantibodies' increased production against autoantigens and enhanced immune complex deposition. Both T- and B-cells with different phenotypes are also involved in SLE's pathogenesis [12]. Previous studies on a subset of B cells with modulatory properties in patients with RA, primary Sjogren's syndrome $(\mathrm{SjS})$, and SLE have demonstrated a hyperfunction in these B cells anti-inflammatory cytokines like IL10 production and eventually homeostasis $[9,13,14]$. Several investigations have shown that depletion of pan B cell could help SLE patients, while phase III trials of the pan-B cell depletion were unsuccessful [15]. This problem can be due to the depletion of both the effector and regulatory B cell subsets [6]. These findings could accordingly confirm the immune-modulatory properties of Bregs and their involvement in the homeostasis mechanisms [16]. The first clinical investigation of peripheral blood B cells in SLE patients revealed that the proportion of $\mathrm{CD}^{+} \mathrm{B}$ cells producing IL-10 was significantly higher than healthy subjects [17]. Although there are several contradictions in this field, some studies have shown that the number of Bregs in autoimmune diseases such as RA and SLE decreased [13]; on the other hand, some experimental and human studies have demonstrated that the number of Bregs was increased in SLE which can ultimately depend on various factors such as treatment protocol and disease activity. In this study, the results show that apart from the number, a group of $\mathrm{B}$ cells might be hyperactivated to cause homeostasis in patients with lower SLEDAI scores [17-21]. In line with our findings, it was shown that in humans, $\mathrm{IL}-10^{+} \mathrm{B}$ cell frequency in SLE patients was higher than the healthy control group $[17,20]$. These findings also confirm the possibility of hyperactive Bregs involvement in balancing inflammatory and anti-inflammatory responses. Although mechanisms that mediate development and induction of the Bregs have thus far remained unclear, a study suggested that the increased IL- $10^{+}$ Bregs may be secondary to expanded $T$ follicular helper (Tfh) cells provide help to effector B cells and promote autoimmunity. Tfh cell and $\mathrm{IL}-10^{+}$Bregs are increased in SLE and Tfh cell-derived IL-21 induced IL-10 [22]. In most human studies that have been done so far, SLE patients were under different treatment protocols, affecting the outcomes [13]. For instance, methotrexate can increase the number and possibly, the activity of B cells [23]. Another study on murine collagen-induced arthritis showed that treating animals with methotrexate, alone or together with cyclophosphamide, can reduce Bregs and DCs in lymph nodes and spleen [24]. 
Table 3 bootstrap linear regression with 95\% bias-corrected confidence interval (Cl) for evaluation of the association between SLEDAI scores and cytokines adjusted to autoantibodies in SLE patients

\begin{tabular}{lll}
\hline Variables & Estimate & $\begin{array}{l}\text { 95\%Cl } \\
\text { (Lower, Upper) }\end{array}$ \\
\hline (Intercept) & 9.936 & $(6.444,36.227)$ \\
Component 1 & -0.438 & $(-1.468,4.987)$ \\
Component 2 & -1.399 & $(-3.089,-0.458)$ \\
Anti dsDNA (Positive) & 0.000 & $(-1.358,1.920)$ \\
ANA (Positive) & -0.186 & $(-13.723,1.490)$ \\
Anti-SSA/Ro (Positive) & -0.854 & $(-2.174,11.219)$ \\
\hline
\end{tabular}

Components 1 and 2 are related to cytokines, * significant association

In contrast, another investigation reported no associations between azathioprine, methotrexate, mycophenolate mofetil, and hydroxychloroquine with the expression of IL-10. However, the mentioned study showed that the serum level of IL-10 was twice more in SLE patients with Asian ethnicity than non-Asians [25]. The results of this study show that patients' ethnicity can also affect the level of anti-inflammatory cytokines. Recently it has been shown that systemic treatment with methotrexate may cause dysregulation of antiinflammatory cytokines [26]. According to the mentioned studies, it seems that treatment with immunomodulatory drugs can change the cytokine profile and negatively affect the results. In our study, the results showed that in newly diagnosed SLE patients with mild or moderate disease activity who were not under any treatment, anti-inflammatory cytokines as well as inhibitory molecules (as suppressive indicators of B cells) expression increased by isolated $\mathrm{B}$ cells in compared to healthy subjects and by increasing the SLEDAI score, serum levels of IL-10 and TGF- $\beta$ decreased remarkably. However, the balance between regulatory and effector functions is a finely regulated immunological process that is not fully understood.

In this study, it was observed that IL-35 levels significantly elevated in SLE patients compared to healthy subjects. In this regard, an investigation reported that IL-35 could induce B cells and stimulate their differentiation into a regulatory subset producing IL-35 and IL-10. These findings similarly proposed that IL- 35 is a potential inducer of the autologous and IL- $35^{+} \mathrm{B}$ cells in treating inflammatory and autoimmune diseases [27]. It had been further confirmed that circulatory IL- $10^{+}$Bregs had significantly increased in SLE patients, accompanied by fluctuation such that the number and activity of the Bregs had elevated during SLE flares and reduced subsequent remission of the disease [22]. Our findings also showed that as the SLEDAI score increased, the levels of IL-10 and TGF- $\beta$ significantly decreased in studied SLE patients, although no decrease was observed in the serum level of IL-35. These findings could confirm the role of disease activity in the fluctuation of the B cells' number and activity in SLE patients.

It should be noted that myeloid-derived suppressor cells (MDSCs) as an immune suppressor cell can also induce the development of Bregs through inducible nitric oxide synthase (iNOS) and relieve self-immune responses in a lupus animal model [28]. Moreover, Bregs are not the only source of immunosuppressive cytokines because other cells might produce and release IL-10, TGF- $\beta$, and IL-35 in response to inflammatory and pathological conditions to modulate the immune response. Evidence showed that the regulatory $\mathrm{T}$ cells (Tregs) and Bregs involvement in different phases of autoimmune diseases could be different. For instance, a study had shown that IL- $10^{+}$Bregs could mainly regulate the initiation phase of the disease, while Tregs could cooperatively inhibit late-phase via covering $\mathrm{IL}-10^{+}$Bregs in an experimental autoimmune encephalomyelitis (EAE) model of multiple sclerosis (MS) disease [29].

Berthelot et al. had reported that induction of apoptosis by Bregs through PD-1, FasL, or TNF-related apoptosis-inducing ligand (TRAIL) differed with the nature of the target $\mathrm{T}$ cell. T-cell subsets' sensitivity probably shifted from Th1 and Th2 to Th17, resulting in a reduction in Tregs [30]. The outputs of this study also demonstrated that the expressions of the PDL- 1 and FasL gene had significantly elevated in isolated B-cells of the patients with SLE compared to healthy subjects. It could be another mechanism of B cell for modulating the immune response by eliminating effector immune cells.

On the other hand, some studies found that regulatory immune cells' function to inhibit effector $\mathrm{T}$ cells in inflammatory and autoimmune illnesses like lupus was defective. However, in most of these investigations, serum levels of IL-35, IL-10, and TGF- $\beta$ cytokines along with PDL-1 and FasL had not been measured in B cells. The wide range of disease activity in SLE patients and treatment protocols might lead to these discrepancies in the studies' findings.

Our findings showed a negative association between serum level of TGF- $\beta$ and SLEDAI; IL-10 and EBI3 genes may be due to reduced Bregs function in patients with higher disease activity scores. However, a positive and significant correlation was observed between the PDL-1 gene and serum level of IL-35, as well as IL-10 and TGF- $\beta$ serum levels [7]. Furthermore, regarding the studied cytokines' extracted data at mRNA and protein levels (components 1 and 2), clustering showed that it is possible to differentiate patients from healthy subjects using the information in components 1 and 2. Additionally, statistical analysis demonstrated that with increasing 
the SLEDAI score, component 2 was significantly decreased. Therefore, with increasing disease activity, the level of immunomodulatory cytokines produced by $\mathrm{B}$ cells in patients with SLE might significantly be decreased.

One of the strengths of this study was that all the patients enrolled in the study were newly diagnosed cases, and blood collection was done before treatment onset because, as discussed before, routine treatment for lupus patients could affect the number and activity of B cells and outcome of the studies [17]. The inaccessibility of the materials for fluorescence-activated cell sorting (FACS) technique to specific isolation and evaluation cytokine levels in Bregs was also declared one of the major limitations of this study.

\section{Conclusion}

Taken together, the results of this study indicated that a group of SLE patients B cells might modulate immune responses in mild to moderate disease activity by producing anti-inflammatory cytokines and expressing inhibitory molecules. The findings can also clarify SLE disease activity's effect on the fluctuation and expression of IL-10, TGF- $\beta$ serum levels. However, the source of the studied cytokines might be other regulatory immune cells. Future studies are needed to fully elucidate the source of released antiinflammatory cytokines and evaluate the producer regulatory cells' number and activity to a well understanding of the immunomodulatory mechanisms in SLE.

\section{Methods}

\section{Subjects}

Twenty-three newly diagnosed SLE patients (mean age of $39.6 \pm 13.4$ years) diagnosed by a rheumatology specialist and 30 normal-age and gender-matched healthy subjects with a mean age of $34.95 \pm 10.01$ years have participated in this study. All SLE patients had at least four of the American College of Rheumatology (ACR) revised SLE criteria. Moreover, activities of the SLE disease have been evaluated through Systemic Lupus Erythematosus Disease Activity Index (SLEDAI), and all the patients showed active SLE (SLEDAI score $>4$ ). All of the enrolled SLE patients had received no treatment up to the blood collection for the experiments. Additionally, No SLE patient has been receiving immunomodulatory medications include antimalarials, at the time of examination. Informed consent was received from each SLE patient and healthy subjects based on Declaration of Helsinki (DoH). Moreover, this investigation was approved by the Ethics Committee of Rafsanjan University of Medical Sciences, Rafsanjan, Iran (IR.RUMS.REC.1389.206).

\section{Cytokine assay}

Five $\mathrm{mL}$ of peripheral blood was obtained from the studied groups, and separation of serums was performed by low-speed centrifugation. Then, serum samples were kept at $-20^{\circ} \mathrm{C}$ for further experiments. Next, ELISA kits were used in order to measure circulatory levels of anti-nuclear antibody (ANA) (TECA N, IBL, Hamburg, Germany), IL-10 (Abnova, KA0125, Taiwan), IL-35 (Cosabio, CSB E13126h, Wuhan, China), and TGF- $\beta$ (Abnova, KA3108, Taiwan) based on the assay procedures documented in the users' instructions manual provided by the manufacturers. The coefficients of variation of intra- and inter-assays were 5 and $15 \%$, respectively.

\section{Isolation and storage of peripheral blood mononuclear cells (PBMCs)}

First, to isolate peripheral blood mononuclear cells (PBMCs), peripheral blood samples were gently diluted in PBS. Next, PBMCs were isolated using Ficoll (Lymphodex, Inno-Train, Germany). For further experiments, fresh PBMCs were utilized.

\section{B cells isolation}

A nylon wool fiber (NWF) procedure using nylon woolpack (Polysciences Inc., USA) was employed to separate B cells. Briefly, the column washed with the media contained Dulbecco's phosphate-buffered saline (DPBS) consisting of $5 \%$ heat-inactivated fetal calf serum (FCS), RPMI-1640 with 10\% FCS, Hank's balanced salt solution (HBSS) consisting of $10 \%$ FCS, McCoy's 5A medium with $10 \%$ FCS at $37^{\circ} \mathrm{C}$, Earle's saline (ES) containing 10\% FCS, and prepared column incubated for one hour at $37^{\circ} \mathrm{C}$. Next, $1 \times 10^{8}$ viable PBMCs were added to each column in a volume of 2 $\mathrm{ml}$ of the media. The stop-cock was also opened and allowed the media for draining until the cell volume entered into the packaged wool. The column top was then further washed with an additional $2 \mathrm{ml}$ of the media and allowed the washed column to enter the packaged wool. The other $2-5 \mathrm{ml}$ of the media was added to the column for ensuring that the wool top had been covered with the medium, and it was then incubated for one hour at $37^{\circ} \mathrm{C}$. Besides, nonadherent T-cells have been collected by two washes. Afterward, adherent B-cells were collected by adding the media for filling the column as well as knocking it to dislodge the cells. Therefore, this column was plunged twice, and the collected cells spun down at $1200 \mathrm{rpm}$ for ten minutes, and the supernatant has been removed. Finally, the cell pellet has been re-suspended in approximately $10 \mathrm{ml}$ of the media. 


\section{Flowcytometry}

All antibodies were purchased from R\&D Systems (Minneapolis, MN, USA). Isolated B cells in the previous step were stained with mouse anti-human CD3e PEconjugated monoclonal antibody $(\mathrm{mAB})$ and either mouse anti-human $\mathrm{CD} 19$ fluorescein-conjugated $\mathrm{mAB}$ or mouse $I_{g G_{1}}$ fluorescein isotype control. The samples were read by the Cyflow Space flow cytometer (Partec, Germany), and data were analyzed by Flomax software (Partec, Germany). B cell purity was more than $80 \%$, as measured by CD19 expression (Fig. 5).

\section{Gene expression assay}

Total RNA was extracted from isolated B cells by an RNA extraction kit (Pars Toos: Iran) and converted into cDNA through a cDNA synthesis kit (Pars Toos, Iran) with the random hexamer primer and oligo $(\mathrm{dT})$. The reverse transcription process was performed according to the one-step protocol recommended by the mentioned manufacturer: $25^{\circ} \mathrm{C}$ for $10 \mathrm{~min}$, followed by $47^{\circ} \mathrm{C}$ for $60 \mathrm{~min}$, and the reaction was finished by $85^{\circ} \mathrm{C}$ for five minutes, and finally, the microtubes were chilled on the ice. Moreover, the RT-PCR technique was performed by $\frac{50 n g}{20 \mu \mathrm{L}}$ of the synthesized cDNA (as template), specific forward and reverse primers (concentration of the primers: $0.5 \mu \mathrm{M}$ ), high ROX SYBR Green Master Mix (Takara, Japan), and nuclease-free water using an Applied Biosystems RT-PCR system (ABI, StepOnePlus software, USA) with this program: $1 \mathrm{cycle}$ of $95^{\circ} \mathrm{C}$ for $15 \mathrm{~min}, 40 \mathrm{cy}$ cles of $95^{\circ} \mathrm{C}$ for $5 \mathrm{~s}$, and adjusted annealing temperature for $40 \mathrm{~s}$. Notably, the melting curve protocol was also proceeded later by $10 \mathrm{~s}$ at $95^{\circ} \mathrm{C}$ and then $10 \mathrm{~s}$ each at $0.2^{\circ} \mathrm{C}$ enhancements between 62 and $95{ }^{\circ} \mathrm{C}$. The sequences of the target and the reference genes are shown in Table 4. The RT-PCR was performed in triplicate, and $\beta$-actin was utilized as the reference gene to normalize the target genes' amplified signal. Moreover, the relative expression of the RT-PCR products was equally calculated via the $2^{-\Delta \Delta C t}$ formula. The dissociation phases, melting curve, and the quantitative analysis of data were also completed with the StepOnePlus ${ }^{\oplus}$ software version 2.3 (Applied Biosystem, Foster City, CA, USA).

\section{Statistical analyses}

GraphPad Prism 7.03 (GraphPad Software, San Diego, CA) and the IBM SPSS 20 (SPSS; Inc.; Chicago; IL: USA) were used to fulfill statistical analysis. The onesample Kolmogorov-Smirnov and Shapiro-Wilk tests further assessed the normality of the variables. Differences between the studied groups were also evaluated by Chi-square statistic, independent sample T-test, Mann-Whitney U test, one-way ANOVA (Tukey's multiple comparisons), and Kruskal-Wallis tests. Moreover, the Spearman correlation test was used to verify the correlation between disease activity and serum levels of autoantibodies and cytokines, as well as inhibitory molecules. The principal component analysis (PCA) was used to explore the obtained data from the studied cytokines [31]. Hierarchical Clustering on Principal Components (HCPC) function from the FactoMine $\mathrm{R}$ package was employed to apply an HCA-based on principal component scores estimated from PCA analysis. The Factoextra package was also used to visualize a dendrogram generated by the hierarchical clustering. In addition, a principal component
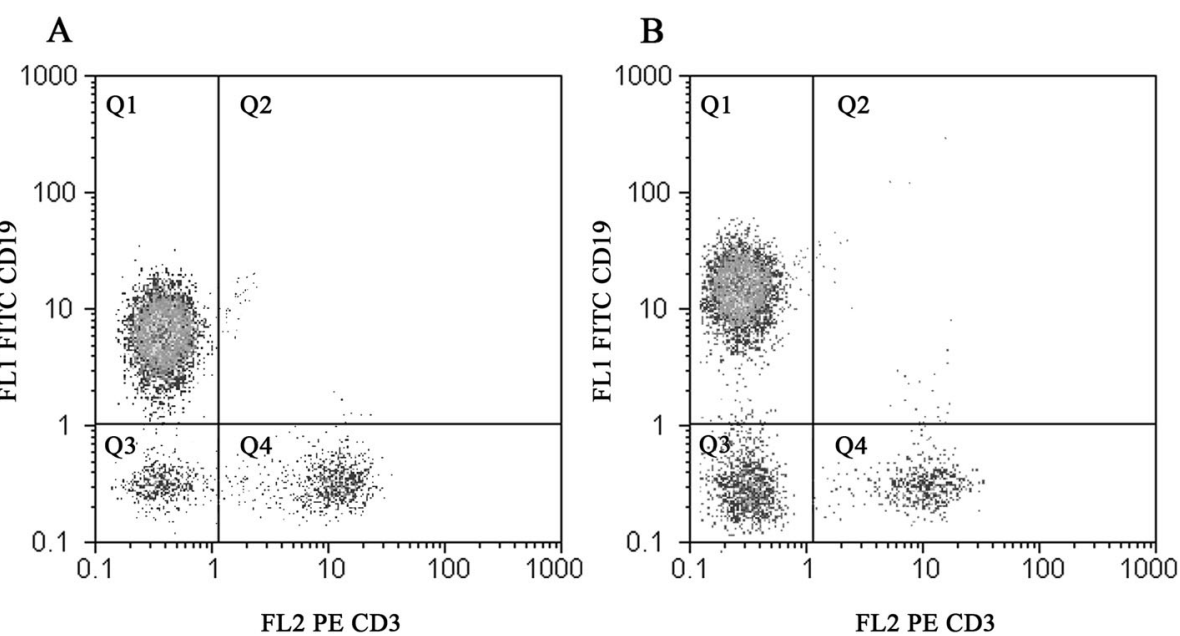

Fig. 5 The expression of CD19+ B cells in healthy subjects (a) and SLE patients (b). Isolated B cells flow cytometry analysis: $C_{1} 19^{+} / C D 3^{-}\left(Q 1, A_{\text {; }}\right.$ $82.97 \pm 9.9 \%, B ; 80.14 \pm 5.7 \%) ; C_{1} 19^{+} / C^{2} 3^{+}(Q 2, A ; 0.9 \pm 0.12 \%, B ; 1.23 \pm 0.27 \%) ; C D 19^{-} / C^{-} 3^{-}(Q 3, A ; 9 \pm 2.5 \%, B ; 10.7 \pm 3.26 \%) ; C D 19^{-} / C^{2} 3^{+}(Q 4$ $A ; 7.13 \pm 2.1 \%, B ; 7.93 \pm 1.99 \%)$. Data are presented as mean $\pm S D$ 
Table 4 The sequences of primers used in the study

\begin{tabular}{lll}
\hline Gene & Forward & Reverse \\
\hline Actin $\beta$ & GCGCGGCTACAGCTTCA & CTTAATGTCACGCACGATTTCC \\
EBI3 & TTCGTGCTTTCATAACAGAGCACATCA & CTCCAGTCACTCAGTTCCCCGTAGTCTG \\
IL-12p35 & ACATGCTGGCAGTTATTGATGA & TGAAGAAGTATGCAGAGCT \\
IL-10 & TTACCTGGAGGAGGTGATGC & GGCCTTGCTCTTGTTTCAC \\
TGF- $\beta$ & CCACCTGCAAGACCATCGAC & CTGGCGAGCCTTAGTTGGAC \\
PDL-1 & AAACAATTAGACCTGGCTG & TCTTACCACTCAGGACTTG \\
FaSL & CTTGGTAGGATTGGGCCTGG & TGTGTGCATCTGGCTGGTAG \\
\hline
\end{tabular}

EBI3 Epstein-Barr Virus Induced 3, TGF- $\beta$ transforming growth factor beta, PDL-1 programmed death-ligand 1, FasL Fas ligand

regression (PCR) test was used to explore the relationship between disease activity (SLEDAI) and cytokines adjusted by auto-antibodies (as potential confounders). Due to the low number of SLE patients, we used a bootstrap technique to inference regression coefficients [32]. All data are presented as mean \pm SD. A $p$-value of less than 0.05 was considered statistically significant.

\section{Abbreviations}

Bregs: Regulatory B-cells; SLE: Systemic lupus erythematosus; ACR: American College of Rheumatology; IL: Interleukin; ELISA: Enzyme-linked immunosorbent assay; TGF- $\beta$ : Transforming growth factor beta; PDL: Programmed death ligand 1; PD-1: Programmed death 1; UV: Ultraviolet light; ds-DNA: Double strain stranded deoxy ribonucleic acid; Sm Ag: Smith antigen; RNPs: Ribonucleoproteins; ANA: Anti-nuclear antibody; T2MZP: Transitional 2-marginal zone precursor; RA: Rheumatoid arthritis; pDCs: Plasmacytoid dendritic cells; IFN-a: Interferon alpha; Th: T helper; NK: Natural killer; SLEDAI: Systemic lupus erythematosus disease activity index; DoH: Declaration of Helsinki; NWF: Nylon wool fiber; PBMC: Peripheral blood mononuclear cell; PCA: Principal component analysis; HCPC: Hierarchical clustering on principal components; PCR: Principal component regression; FACS: Fluorescence-activated cell sorting

\section{Acknowledgments}

Rafsanjan University of Medical Sciences was supported this study.

\section{Authors' contributions}

All authors read and approved the final manuscript. Conception and design: MA, HK. Development of methodology: PS, HK. Acquisition of data (patient interviews, treatment data, assessments of oncologists): HK, MA, AR, ZK, MH. Analysis and interpretation of data: ZK. Writing, review, and/or revision of manuscript: HK. Administrative, technical, or material support: MA, HK

\section{Funding}

No specific funding was obtained for this study.

\section{Availability of data and materials}

The datasets used and/or analyzed during the current study available from the corresponding author on reasonable request.

\section{Ethics approval and consent to participate}

This study was approved by the ethics committee of Rafsanjan University of Medical Sciences. Written informed consent was obtained from all participants. All procedures performed in this study were in accordance with the 1964 Helsinki declaration and its later amendments or comparable ethical standards.

\section{Consent for publication}

Not applicable.

\section{Competing interests}

All authors declare no competing interests.

\section{Author details}

'Department of Internal Medicine, Ali-Ibn Abi-Talib Hospital, School of Medicine; Molecular Medicine Research Center, Research Institute of Basic Medical Sciences, Rafsanjan University of Medical Sciences, Rafsanjan, Iran. ${ }^{2}$ Clinical Research Development Unit, Ali-Ibn Abi-Talib Hospital, Rafsanjan University of Medical Sciences, Rafsanjan, Iran. ${ }^{3}$ Department of Family Medicine, School of Medicine, Rafsanjan University of Medical Sciences, Rafsanjan, Iran. ${ }^{4}$ Department of Pathology, School of Medicine, Rafsanjan University of Medical Sciences, Rafsanjan, Iran. ${ }^{5}$ Department of Immunology, School of Medicine; Molecular Medicine Research Center, Research Institute of Basic Medical Sciences, Rafsanjan University of Medical Sciences, Rafsanjan, Iran.

Received: 30 June 2020 Accepted: 4 November 2020

Published online: 16 November 2020

\section{References}

1. Nagafuchi Y, Shoda H, Fujio K. Immune profiling and precision medicine in systemic lupus Erythematosus. Cells. 2019;8(2):140.

2. Vieira SM, Hiltensperger M, Kumar V, Zegarra-Ruiz D, Dehner C, Khan N, et al. Translocation of a gut pathobiont drives autoimmunity in mice and humans. Science. 2018;359(6380):1156-61.

3. Cozzani E, Drosera M, Gasparini G, Parodi A. Serology of Lupus Erythematosus: Correlation between Immunopathological Features and Clinical Aspects. Autoimmune Diseases. 2014;2014:321359.

4. Wahren-Herlenius M, Dörner T. Immunopathogenic mechanisms of systemic autoimmune disease. Lancet. 2013;382(9894):819-31..

5. Manna A, Aulakh S, Sher T, Ailawadhi S, Chanan-Khan A, Paulus A. CD38hi Bregulatory (B-reg) cells maintain pathological immune tolerance in chronic lymphocytic leukemia (CLL)/B cell diseases: potential therapeutic considerations. Am Assoc Immnol. 2019;202(1 Supplement):71.13-71.13.

6. Matsushita T. Regulatory and effector B cells: friends or foes? J Dermatol Sci. 2019;93(1):2-7.

7. Wang T, Mei Y, Li Z. Research progress on regulatory B cells in Systemic Lupus Erythematosus. Biomed Res Int. 2019;2019:7948687.

8. Mauri C, Bosma A. Immune regulatory function of B cells. Annu Rev Immunol. 2012;30:221-41.

9. Karim MR, Zhang H-Y, Yuan J, Sun Q, Wang Y-F. Regulatory B cells in seropositive myasthenia gravis versus healthy controls. Front Neurol. 2017;8: 43.

10. Menon M, Blair PA, Isenberg DA, Mauri C. A regulatory feedback between plasmacytoid dendritic cells and regulatory B cells is aberrant in systemic lupus erythematosus. Immunity. 2016;44(3):683-97..

11. Yang M, Rui K, Wang S, Lu L. Regulatory B cells in autoimmune diseases. Cell Mol Immunol. 2013;10(2):122.

12. Lipsky PE. Systemic lupus erythematosus: an autoimmune disease of B cell hyperactivity. Nat Immunol. 2001;2(9):764.

13. Blair PA, Noreña LY, Flores-Borja F, Rawlings DJ, Isenberg DA, Ehrenstein MR, et al. CD19+ CD24hiCD38hi B cells exhibit regulatory capacity in healthy individuals but are functionally impaired in systemic lupus erythematosus patients. Immunity. 2010;32(1):129-40.

14. Habib J, Deng J, Lava N, Tyor W, Galipeau J. Blood B cell and regulatory subset content in multiple sclerosis patients. J Mult Scler (Foster City). 2015; 2(2):1000139. 
15. Merrill JT, Neuwelt CM, Wallace DJ, Shanahan JC, Latinis KM, Oates JC, et al. Efficacy and safety of rituximab in moderately-to-severely active systemic lupus erythematosus: the randomized, double-blind, phase II/III systemic lupus erythematosus evaluation of rituximab trial. Arthritis \& Rheumatism. 2010;62(1):222-33.

16. Matsushita T. Regulatory B cells in mouse models of Systemic Lupus Erythematosus (SLE). In: Vitale G, Mion F, editors. Regulatory B cells: methods and protocols. New York, NY: Springer New York; 2014. p. 195-205.

17. Kashipaz MA, Huggins M, Lanyon P, Robins A, Powell R, Todd I. Assessment of Be1 and Be2 cells in systemic lupus erythematosus indicates elevated interleukin-10 producing CD5+ B cells. Lupus. 2003;12(5):356-63.

18. Watanabe $R$, Ishiura N, Nakashima H, Kuwano $Y$, Okochi H, Tamaki K, et al. Regulatory B cells (B10 cells) have a suppressive role in murine lupus: CD19 and B10 cell deficiency exacerbates systemic autoimmunity. J Immunol. 2010;184(9):4801-9.

19. Díaz-Alderete A, Crispin JC, Vargas-Rojas MI, Alcocer-Varela J. IL-10 production in B cells is confined to CD154+ cells in patients with systemic lupus erythematosus. J Autoimmun. 2004;23(4):379-83.

20. Iwata Y, Matsushita T, Horikawa M, DiLillo DJ, Yanaba K, Venturi GM, et al. Characterization of a rare IL-10-competent B-cell subset in humans that parallels mouse regulatory B10 cells. Blood. 2011;117(2):530-41.

21. Vadasz Z, Peri R, Eiza N, Slobodin G, Balbir-Gurman A, Toubi E. The expansion of CD25highlL-10highFoxP3high B regulatory cells is in association with SLE disease activity. J Immunol Res. 2015:2015:254245.

22. Yang $X$, Yang J, Chu Y, Xue Y, Xuan D, Zheng S, et al. T follicular helper cells and regulatory $B$ cells dynamics in systemic lupus erythematosus. PLoS One. 2014;9(2):e88441

23. Piper CJ, Wilkinson MGL, Deakin CT, Otto GW, Dowle S, Duurland CL, et al. CD19+ CD24hiCD38hi B cells are expanded in juvenile dermatomyositis and exhibit a pro-inflammatory phenotype after activation through toll-like receptor 7 and interferon-a. Front Immunol. 2018:9:1372.

24. Fan J, Luo J, Yan C, Hao R, Zhao X, Jia R, et al. Methotrexate, combined with cyclophosphamide attenuates murine collagen induced arthritis by modulating the expression level of Breg and DCs. Mol Immunol. 2017;90: 106-17.

25. Godsell J, Rudloff I, Kandane-Rathnayake R, Hoi A, Nold MF, Morand EF, et al. Clinical associations of IL-10 and IL-37 in systemic lupus erythematosus. Sci Rep. 2016;6:34604.

26. Zdanowska N, Owczarczyk-Saczonek A, Czerwińska J, Nowakowski JJ, Kozera-Żywczyk A, Owczarek W, et al. Adalimumab and methotrexate affect the concentrations of regulatory cytokines (interleukin-10, transforming growth factor- $\beta 1$, and interleukin-35) in patients with plaque psoriasis. Dermatologic Ther. 2020;14:e14153.

27. Wang R-X, Yu C-R, Dambuza IM, Mahdi RM, Dolinska MB, Sergeev $Y$, et al. Interleukin-35 induces regulatory B cells that suppress autoimmune disease. Nat Med. 2014;20(6):633.

28. Park MJ, Lee SH, Kim EK, Lee EJ, Park SH, Kwok SK, et al. Myeloid-derived suppressor cells induce the expansion of regulatory $\mathrm{B}$ cells and ameliorate autoimmunity in the sanroque mouse model of systemic lupus erythematosus. Arthritis \& Rheumatology. 2016;68(11):2717-27.

29. Matsushita T, Horikawa M, Iwata Y, Tedder TF. Regulatory B cells (B10 cells) and regulatory $T$ cells have independent roles in controlling experimental autoimmune encephalomyelitis initiation and late-phase immunopathogenesis. J Immunol. 2010;185(4):2240-52.

30. Berthelot J-M, Jamin C, Amrouche K, Le Goff B, Maugars Y, Youinou P. Regulatory B cells play a key role in immune system balance. Joint Bone Spine. 2013;80(1):18-22.

31. Lê S, Josse J, Husson F. FactoMineR: an R package for multivariate analysis. J Stat Softw. 2008:25(1):1-18.

32. Canty A, Ripley B. boot: Bootstrap R (S-Plus) Functions [Software]; 2016.

\section{Publisher's Note}

Springer Nature remains neutral with regard to jurisdictional claims in published maps and institutional affiliations.

\section{Ready to submit your research? Choose BMC and benefit from:}

- fast, convenient online submission

- thorough peer review by experienced researchers in your field

- rapid publication on acceptance

- support for research data, including large and complex data types

- gold Open Access which fosters wider collaboration and increased citations

- maximum visibility for your research: over $100 \mathrm{M}$ website views per year

At BMC, research is always in progress.

Learn more biomedcentral.com/submissions 